\title{
Human breast carcinomal tissues display distinctive FTIR spectra: implication for the histological characterization of carcinomas
}

\author{
Tiyu Gao, Jun Feng and Yunxiang $\mathrm{Ci}^{*}$ \\ Department of Chemistry, Peking University, Beijing \\ 100871, China
}

Received 24 July 1998

Revised 6 January 1999

Accepted 17 February 1999

Fourier transform infrared spectroscopic study of human breast normal and carcinomal tissues has been carried out. Some distinctive spectral differences which are mainly due to nucleic acids and proteins are observed between normal and carcinomal tissues. This method of analysis results in nearly $100 \%$ diagnostic accuracy of carcinomal tissues from normal tissues. The spectral patterns of well-differentiated carcinomal tissues exhibit marked heterogeneity, however that of poorly differentiated carcinomas demonstrate significant similarity. Apocrine, tubular, intraductal and mucinous carcinomas and invasive infiltrating ductal carcinomal tissues can be discriminated based on their characteristic spectra. The spectral differences confirm the possibility of using FTIR as an accurate and rapid technique to distinguish between normal and malignant breast tissues and classify breast carcinomas in different subtypes.

Keywords: Infrared spectroscopic features, breast carcinomal tissues, clinical classification

\section{Introduction}

Breast cancer is a world-wide and frequent disease among women. Histopathological examination, mammographic or ultrasonic imaging, computerized tomography, magnetic resonance imaging [1], flow cytometry [2], and biological markers [3] have been used to detect the malignancy of breast tissues. How-

*Corresponding author: Department of Chemistry, Peking University, Beijing, China, 100871. Tel.: 008610 62751499; Fax: 008610 62751708; E-mail: ciyx@chemms.chem.pku.edu.cn. ever, these methods are either subjective, imprecise, labour intensive or costly. Alternative detecting methods which are accurate, inexpensive and rapid are required. And in fact, other techniques have been under investigation for reducing the current reliance on the traditional diagnostic methods. Fourier transform infrared (FTIR) spectroscopic analysis represents a powerful tool since it can furnish important indications of the biological and physicological alterations of tissues or cells which are related to the changes of components, molecular structures and intra-/intermolecular interactions. This physical method has been applied to examine normal and neoplastic cells or tissues: leukemic lymphocytes and lymphoblasts [4-7], human cervical cells during carcinogenesis [8-13], human colon adenocarcinoma cell lines [14,15], lung tumour cells [16,17], skin tumour [18] and human breast tumours $[19,20]$. Among them, the spectral differences between normal and malignant cells or tissues were intensively studied. Breast cancer presents varied histological types, but the spectral differences among the histological types of breast carcinomal tissues are rarely reported. The purpose of this study is to assess the possibility of using FTIR spectroscopy to distinguish between normal and malignant breast tissues and to classify the carcinomal tissues in different subtypes.

\section{Experimental}

\subsection{Materials and procedures}

Forty two surgical specimens of human breast tissues were obtained from breast resection (lumpectomy and mastectomy) in the First People's Hospital, Beijing Medical University. Each sample was cut into two pieces, the first was sent to the pathologists for evaluation by standard pathological methods; the second was washed with $0.9 \% \mathrm{NaCl}$ solution and frozen 
in liquid nitrogen immediately after collection until used for IR spectroscopic studies. Small amounts of the frozen tissue sample was minced, then dispersed, and finally centrifuged [16]. The cell suspension was evenly spread over the surface of a specially designed infrared window of $\mathrm{BaF}_{2}$, then the sample was placed in a vacuum desiccator and allowed to dry to form a even film. Among them, 11 samples were diagnosed cytologically as invasive infiltrating ductal carcinoma (IIDC) tissues; 8 samples were diagnosed as IIDC with a predominant intraductal component; 3, 4, 4, 5, 3 samples were diagnosed as aprocine, tubular, mucious, simplex and medullary carcinomal tissues, respectively. Normal breast tissues were from 6 noncancerous patients.

\subsection{Apparatus and data analysis}

Infrared spectra in the $400-4000 \mathrm{~cm}^{-1}$ region were recorded on a Bruker Vector 22 Fourier transform spectrometer equipped with an air-cooled DTGS detector. Infrared window of $\mathrm{BaF}_{2}$ without cell suspension was scanned as the background for each spectrum; 512 scans were co-added at a spectral resolution of $2 \mathrm{~cm}^{-1}$. Residual water vapor was interactively subtracted. To minimize problems from avoidable baseline shifts, the spectra were baseline-corrected.

\section{Results}

\subsection{The spectra and the assignment of the absorption bands of carcinomal tissues}

At the beginning of this investigation, many tests were carried out to obtain samples giving reliable and reproducible spectra. Two or three spectroscopic samples were prepared and determined for each tissue. As shown in Fig. 1 (A and B), the infrared spectral patterns of the human breast normal and IIDC tissues exhibit an appreciable degree of reproducibility in our experiments. The representative superimposed spectra of normal and IIDC are shown in Fig. 2. The representative infrared spectra in the frequency region 950 to $1500 \mathrm{~cm}^{-1}$ of the well-differentiated and poorly differentiated carcinomal tissues are shown in Fig. 3 and Fig. 4, respectively. The typical infrared spectra in the frequency region 2800 to $3050 \mathrm{~cm}^{-1}$ of carcinomal tissues are shown in Fig. 5. Based on the previous IR studies on cellular organelles and macromolecules [4,14-16,20,21], the assignment of infrared bands of breast tissues can be established. As shown in Figs 1-4, the weak and broad peak near $970 \mathrm{~cm}^{-1}$ is generally assigned to the symmetric stretching mode of dianionic phosphate monoester of cellular nucleic acids. The bands near $1032 \mathrm{~cm}^{-1}$ and $1052 \mathrm{~cm}^{-1}$ are mainly from the vibrational modes of $-\mathrm{CH}_{2} \mathrm{OH}$ groups and the $\mathrm{C}-\mathrm{O}$ stretching coupled with $\mathrm{C}-\mathrm{O}$ bending of the $\mathrm{C}-\mathrm{OH}$ groups of carbohydrates and carbohydrate residues. The peaks near $1083 \mathrm{~cm}^{-1}$ and $1238 \mathrm{~cm}^{-1}$ are from both collagen and nucleic acid. The bands at $1083 \mathrm{~cm}^{-1}$ is due mainly to the symmetric phosphate $\left(\mathrm{PO}_{2}^{-}\right)$stretching modes $\left(\nu \mathrm{s} \mathrm{PO}_{2}^{-}\right)$of nucleic acids and the vibrational modes of collagen carbohydrates residues, and $1238 \mathrm{~cm}^{-1}$ is due to the asymmetric phosphate $\left(\mathrm{PO}_{2}^{-}\right)$stretching modes $\left(\nu\right.$ as $\left.\mathrm{PO}_{2}^{-}\right)$of nucleic acids and the amide III/ $\mathrm{CH}_{2}$ wagging vibrations of collagen. As for the absorption band at $1095 \mathrm{~cm}^{-1}$ in the spectrum of the tubular carcinomal tissue, it can be assigned to the degenerate stretching of dianionic phosphate monoester [21]. The peaks near 1205, 1281 and $1338 \mathrm{~cm}^{-1}$ arise from the amide III/CH $\mathrm{CH}_{2}$ wagging vibrations of collagen [20]. The band near $1164 \mathrm{~cm}^{-1}$ can be assigned to the $\mathrm{C}-\mathrm{O}$ stretching modes of the $\mathrm{C}-\mathrm{OH}$ groups of cell proteins and the $\mathrm{C}-\mathrm{O}$ groups of carbohydrates. The weak peaks near $1400 \mathrm{~cm}^{-1}$ and $1456 \mathrm{~cm}^{-1}$ mainly arise from the symmetric and asymmetric bending vibrational modes of methyl groups of proteins $\left(\delta \mathrm{s} \mathrm{CH}_{3}\right.$ and $\delta$ as $\left.\mathrm{CH}_{3}\right)$, respectively. Peaks near $2853 \mathrm{~cm}^{-1}$ and $2925 \mathrm{~cm}^{-1}$ originate from $\nu \mathrm{s} \mathrm{CH}_{2}$ and $\nu$ as $\mathrm{CH}_{2}, 2958 \mathrm{~cm}^{-1}$ is from $\nu$ as $\mathrm{CH}_{3}$ of proteins, lipids and DNA.

\subsection{The spectroscopic differences between normal and IIDC tissues}

As shown in Fig. 2, some remarkable spectral differences can be observed between the normal and IIDC tissue samples. The predominant differences include the following findings. Firstly, the peak at $970 \mathrm{~cm}^{-1}$ is sharper and stronger, the intensity of the peak near $1032 \mathrm{~cm}^{-1}$ is decreased sharply and the peak almost disappears; the serious bands at 1205, 1281 and $1338 \mathrm{~cm}^{-1}$ are weaker and broader for carcinomal tissue whereas the band near $970 \mathrm{~cm}^{-1}$ is weaker and almost disappears. The serious peaks of collagen are sharper and stronger for normal tissues. These results imply the increase of nucleic acids and the decrease of the relative content of collagen in carcinomal tissues. Secondly, the band near $1164 \mathrm{~cm}^{-1}$ band in normal tissues shifts to $1169 \mathrm{~cm}^{-1}$ in carcinomal tissue. The shift of about $5 \mathrm{~cm}^{-1}$ of the frequency in the IIDC 

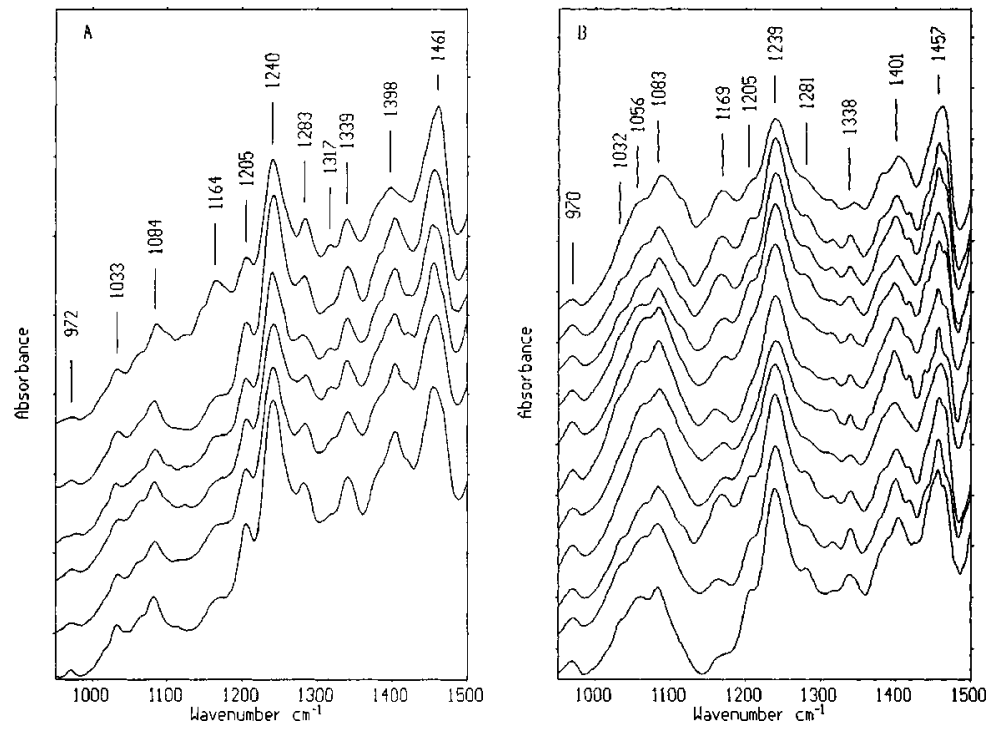

Fig. 1. This figure shows the appreciable reproducibility of the FTIR spectra in the frequency region 950 to $1500 \mathrm{~cm}^{-1}$ of human breast normal tissues (A) and invasive infiltrating ductal carcinomal tissues (B).
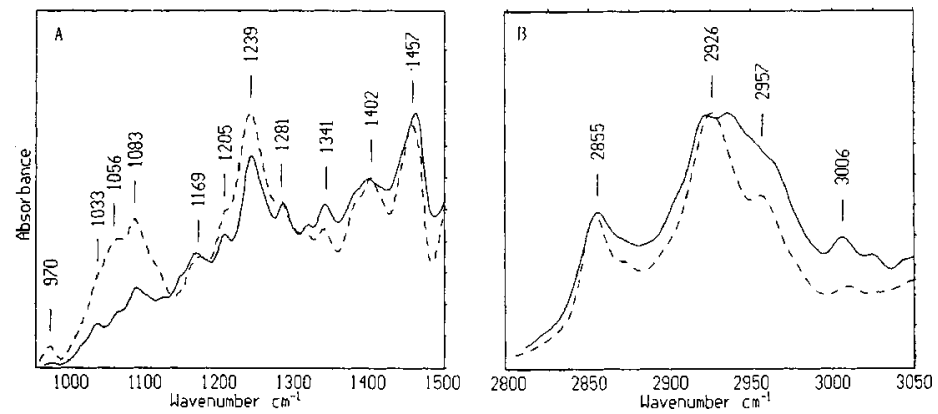

Fig. 2. This figure shows the remarkable spectral differences between human breast normal tissues (-) and invasive infiltrating ductal carcinomal tissues (- - ) in the frequency region 950 to $1500 \mathrm{~cm}^{-1}$ (A) and 2800 to $3050 \mathrm{~cm}^{-1}$ (B): the peak at $970 \mathrm{~cm}^{-1}$ is sharper and stronger, the serious bands at 1205, 1281 and $1338 \mathrm{~cm}^{-1}$ are weaker and broader for carcinomal tissue than that for normal tissues; the band near $1164 \mathrm{~cm}^{-1}$ band in normal tissues shifts to $1169 \mathrm{~cm}^{-1}$ in carcinomal tissue; the absorbance ratio $\mathrm{A}_{2958} / \mathrm{A}_{2853}$ in carcinomal tissue is smaller than that of normal tissue. These results imply the increase of nucleic acids and the decrease of the relative content of collagen in carcinomal tissues.

samples was observed, and the shift indicates the increase of malignant cells in carcinomal tissue, because the band near $1169 \mathrm{~cm}^{-1}$ band is mainly attributed to the $\mathrm{C}-\mathrm{O}$ stretching mode of phosphorylated proteins in parenchymal cells [14] or is mainly from malignant epithelial cells [15]. Thirdly, infrared spectra in the frequency region 2800 to $3050 \mathrm{~cm}^{-1}$ of normal and carcinomal tissues are shown in Fig. 2B. The band at $2853 \mathrm{~cm}^{-1}$ is mainly due to the $\nu$ as $\mathrm{CH}_{2}$ mode, the $2958 \mathrm{~cm}^{-1}$ band is due to the $\nu$ as $\mathrm{CH}_{3}$ mode. The absorbance ratio between the methyl stretching band and methylene band $\mathrm{A}_{2958} / \mathrm{A}_{2853}$ in carcinomal tissue is smaller than that of normal tissue. This trend indicates a decrease in number of methyl groups com- pared to methylene groups in IIDC tissue. The slight decrease of $A_{2958} / A_{2853}$ ratio from normal epithelium to malignant epithelium or to malignant tissues was observed $[10,15]$ and explained as the results of hypomethylation [22]. However, compared to normal and malignant epithelial tissues, the $\mathrm{A}_{2958} / \mathrm{A}_{2853}$ ratio increases dramatically in connective tissue and this result was explained as the main contribution of the large number of methyl groups in protein fibers [15]. Therefore, the decrease of $\mathrm{A}_{2958} / \mathrm{A}_{2853}$ ratios in carcinomal tissues may be contributed from three factors: hypomethylation of DNA [22], the increase of malignant epithelial components and the decrease of protein fibers in carcinomas, but the latter two are the main factors. 

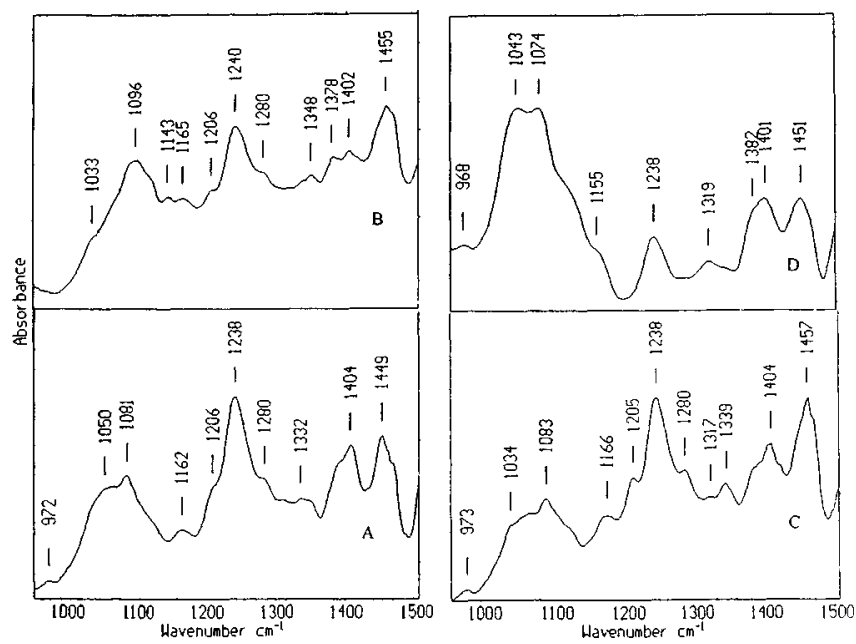

Fig. 3. This figure shows the significant differences among the representative FTIR spectra in the frequency region 950 to $1500 \mathrm{~cm}^{-1}$ of human breast (A) apocrine, (B) tubular, (C) intraductal, (D) mucinous carcinoma: the spectral patterns of apocrine and mucinous carcinomas are completely different from others; $\mathrm{A}_{1449} / \mathrm{A}_{1404} \approx 1.0$ in apocrine carcinoma whereas $\mathrm{A}_{1457} / \mathrm{A}_{1404} \gg 1.0$ in intraductal carcinoma.

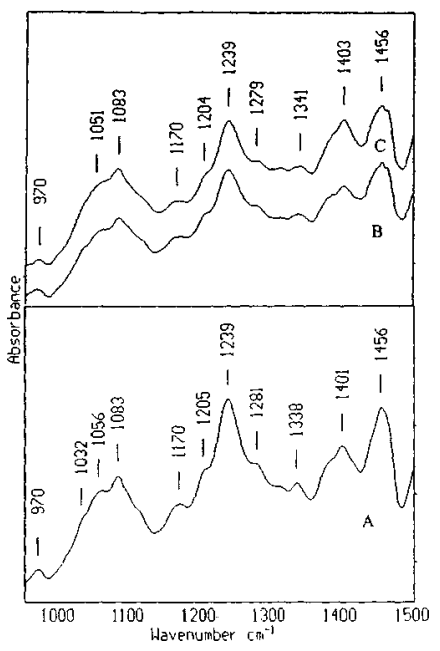

Fig. 4. This figure shows the differences among the representative FTIR spectra in the frequency region 950 to $1500 \mathrm{~cm}^{-1}$ of human breast (A) invasive infiltrating ductal carcinoma (IIDC), (B) simplex, (C) medullary carcinomas: this band near $1170 \mathrm{~cm}^{-1}$ in IIDC sample is sharper and stronger than that in simplex and medullary carcinomas; the ratio of $\mathrm{A}_{1238} / \mathrm{A}_{1403}$ in the spectrum of simplex carcinomal tissue is lower than that of medullary carcinoma.

\subsection{The spectroscopic comparison of carcinomal tissues}

Figures 3 and 4 represent the spectra of the well and poorly differentiated carcinomas, respectively. These spectra exhibit their characteristic differences and the important spectroscopic parameters are listed in Table 1 . In the spectrum of apocrine carcinomal tissue, the intensity of band at $1404 \mathrm{~cm}^{-1}$ is almost simi- lar to that of at $1449 \mathrm{~cm}^{-1}$, but they are lower than that at $1238 \mathrm{~cm}^{-1}$. The peak at $970 \mathrm{~cm}^{-1}$ disappears, while a strong absorption band at $1096 \mathrm{~cm}^{-1}$ from the degenerate stretching of dianionic phosphate monoester emerges and overlaps the band of $\nu \mathrm{s} \mathrm{PO}_{2}^{-}$at $1083 \mathrm{~cm}^{-1}$ in the spectrum of tubular carcinomal tissues. In the intraductal carcinomal tissue, the relative intensities of bands at 1205 and $1280 \mathrm{~cm}^{-1}$, which are from the collagen, are the strongest in all the carcinoma samples, the intensity of the peak at $1034 \mathrm{~cm}^{-1}$ is almost similar to that at $1050 \mathrm{~cm}^{-1}$. As for the mucinous carcinomal tissue, the main peaks between $1025-$ $1180 \mathrm{~cm}^{-1}$ appearing at 1043, 1076 and $1155 \mathrm{~cm}^{-1}$, are completely different from the bands appearing at $1032,1055,1083$ and $1166 \mathrm{~cm}^{-1}$ in other carcinoma samples. The collagen absorption bands at 1204 and $1280 \mathrm{~cm}^{-1}$ disappear in mucinous carcinomal tissue. This result indicates the relative content of collagen is very low in mucinous carcinomal tissue. In poorly differentiated carcinomas, the most remarkable feature is the appearance of the band at $1170 \mathrm{~cm}^{-1}$, which positively shifts $4-10 \mathrm{~cm}^{-1}$ compared to that of other carcinoma samples, but this band in IIDC sample is sharper and stronger than that in simplex and medullary carcinomas. The spectroscopic profile of simplex carcinomal tissue is similar to that of medullary carcinomal tissue, but the relative intensity ratios of main bands are considerably different. The ratio of $\mathrm{A}_{1238} / \mathrm{A}_{1403}$ in the spectrum of simplex carcinomal tissue is much higher than that in medullary carcinoma. As shown in Fig. 5, among the intensity ratios of $\mathrm{A}_{2958} / \mathrm{A}_{2853}$ of carcino- 
Table 1

The FTIR spectroscopic parameters of breast carcinomal tissues

\begin{tabular}{lcccccc}
\hline Tissue/Parameter & \multicolumn{3}{c}{$1025 \sim 1100$} & 1160 & $\mathrm{~A}_{1453} / \mathrm{A}_{1240}$ & $\mathrm{~A}_{1453} / \mathrm{A}_{1403}$ \\
\hline Aprocrine & 1031 & 1050 & 1081 & 1162 & $<1.0$ & $\approx 1.0$ \\
Tubular & 1033 & & 1096 & 1165 & $>1.0$ & $\gg 1.0$ \\
Intraductal & 1034 & 1055 & 1083 & 1166 & $\approx 1.0$ & $\gg 1.0$ \\
Mucinous & 1043 & 1076 & & 1155 & $>1.0$ & $\approx 1.0$ \\
IIDC & 1032 & 1056 & 1083 & 1170 & $<1.0$ & $>1.0$ \\
Simplex & 1033 & 1051 & 1083 & 1170 & $>1.0$ & $\gg 1.0$ \\
Medullary & 1033 & 1051 & 1083 & 1170 & $>1.0$ & $>1.0$ \\
\hline
\end{tabular}

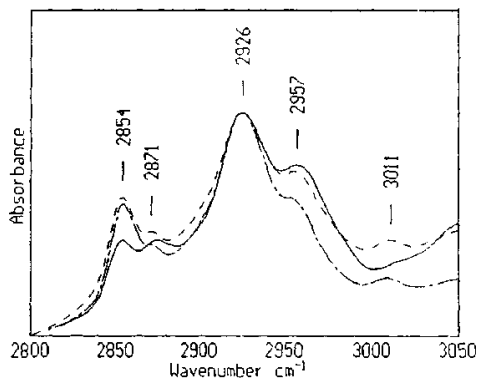

Fig. 5. This figure shows the differences of $A_{2958} / A_{2853}$ : the ratio is the highest in (a) tubular carcinoma (-), almost similar in (b) other carcinomal tissues such as invasive infiltrating ductal medullary carcinomal tissues (-- ), the smallest in (c) mucinous carcinoma (- - -).

mal tissues, the ratio in tubular carcinomal tissue is the highest, that in mucinous carcinoma is the smallest, but the ratios in other carcinomas are almost similar. The results are consistent with the changes of the relative content of collagen histologically observed in breast carcinomal tissues [23]. Thus, the differences of $\mathrm{A}_{2953} / \mathrm{A}_{2853}$ ratio in tubular, mucinous and IIDC carcinomal tissues are mainly from the differences of the relative content of collagen in these tissues. Summarily, the spectra of carcinomal tissues show some distinct differences in spectroscopic parameters such as the profile, the band frequencies, the relative intensity ratio, and these spectroscopic differences can be used to classify the carcinomal tissues.

Furthermore, the spectra of well-differentiated and poorly differentiated carcinomas also demonstrate some different spectral features. The absorption bands between $1032-1180 \mathrm{~cm}^{-1}$ in well-differentiated carcinomal tissues exhibit marked heterogeneity, whereas the spectral profiles in poorly differentiated carcinomas are almost similar. Figure 6 shows the absorption band in the frequency region 1140 to $1180 \mathrm{~cm}^{-1}$. For well differentiated carcinomas, the band emerges peaking below $1167 \mathrm{~cm}^{-1}$; for poorly differentiated carcinoma, the band is broader, and is composed two bands

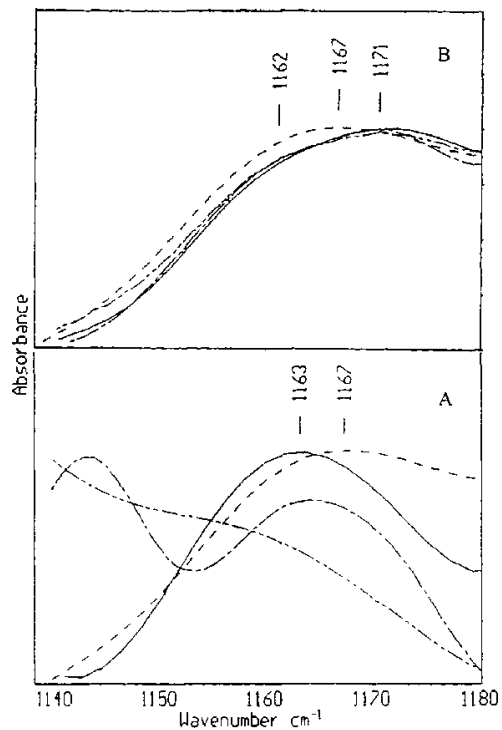

Fig. 6. This figure shows the spectral differences in the region of 1140-1180 $\mathrm{cm}^{-1}$ between (A) well differentiated carcinomas: (a) apocrine (-), (b) tubular (- - - -), (c) intraductal (-- -), (d) mucinous (- - - - -) and (B) poorly differentiated carcinomas: (a) invasive infiltrating ductal (-), (b) simplex ( - - - -), (c) medullary carcinoma (_ - - _ - -), (d) intraductal (- - ): the band of well differentiated carcinoma emerges peaking below $1167 \mathrm{~cm}^{-1}$, the band of poorly differentiated carcinoma is broader, and is composed two bands peaking at $1162 \mathrm{~cm}^{-1}$ and $1170 \mathrm{~cm}^{-1}$.

peaking at 1162 and $1170 \mathrm{~cm}^{-1}$. These results may reflect the heterogeneity in well-differentiated carcinomas and the higher relative content malignant epithelial cells in poorly differentiated carcinomas.

\section{Discussion}

Breast carcinoma is a very heterogeneous disease clinically and pathologically. The differences of the character or composition of carcinoma result in variation of the chemical compositions of the carcinomas. Some distinctive spectral differences which are 
mainly due to nucleic acids and proteins are observed between normal and malignant breast tissues. This method of analysis results in nearly $100 \%$ diagnostic accuracy of carcinomal tissues from normal tissues. The spectral patterns of well-differentiated carcinomal tissues exhibit marked heterogeneity, but the profiles of poorly differentiated carcinomas demonstrate significant similarity. Apocrine, tubular, intraductal, mucinous, IIDC carcinomal tissues can be discriminated from each other based on their characteristic spectra. However, more cases and effort are needed to distinguish between simplex and medullary carcinomal tissues. Nonetheless, FTIR spectroscopic analysis at the molecular level demonstrate a significance in aiding histological characterization of breast carcinomal tissues. This method is inexpensive, possible to automate, and requires minimal amounts of samples and can be of great assistance to the practicing clinician. The establishment of an analytical system of breast carcinomal tissues is in progress in our laboratory.

\section{Acknowledgements}

We thank Prof. Xiu Kan and Dr Jian Xiang Dong at Department of Pathology, the first People's Hospital, Beijing Medical University for providing and evaluating the samples. This project was supported by National Natural Science Foundation of China. No. 39730160.

\section{References}

[1] J.M. Dixon and R.E. Mansel, ABC of breast disease: symptoms, assessment and guidelines for referral, Br. Med. J. 309 (1994), 722-728.

[2] C.D. Osborne, DNA flow cytometry in early breast cancer: a step in the right direction, J. Natl. Cancer Inst. 94 (1989), 6065.

[3] A.K.C. Lee, P.P. Rosen, R.A. DeLellis, P.E. Saigo, M.A. Gangi, S. Groshen, R. Bagin and H.J. Wolfe, Tumor markers expression in breast carcinomas and relationship to prognosis: an immunohistochemical study, Am. J. Clin. Pathol. 84 (1985), 687696.

[4] E. Benedetti, F. Papineschi, P. Verganini, R. Consolini and G. Spremolla, Analytical infrared spectral differences between human normal and leukemic cells (CLL) - I, Leukemia Res. 8 (1984), 483-489.

[5] E. Benedetti, M.P. Palatresi, P. Verganini, F. Papineschi and G. Spremolla, New possibilities of research in chronic lymphatic leukemia by means of Fourier transform infrared spectroscopy - II, Leukemia Research 8 (1985), 483-489.
[6] E. Benedetti, M.P. Palatresi, P. Verganini, F. Papineschi, M.C. Andreucci and G. Spremolla, Infrared characterization of nuclei isolated from normal and leukemic (B-CLL) lymphocytes: part III, Appl. Spectrosc. 40 (1985), 39-43.

[7] C.P. Schults, K.Z. Liu, J.B. Johnston and H.H. Mantsch, Study of chronic lymphocytic leukemia cells by FT-IR spectroscopy and cluster analysis, Leukemia Res. 20 (1996), 649-655.

[8] P.T.T. Wong, R.K. Wong, T. Caputo, T.A. Godwin and B. Ragas, Infrared spectroscopy of exfoliated human cervical cells: evidence of extensive structural changes during carcinogenesis, Proc. Natl. Acad. Sci. USA 88 (1991), 10 988-10 992.

[9] P.T.T. Wong, R.K. Wong and F.K. Fung, FT-IR study of human cervical tissues, Appl. Spectrosc. 47 (1993), 1058-1064.

[10] M.F.K. Fung, M.K. Senterman, N.Z. Mikhael, S. Lacelle and P.T.T. Wong, Pressure-tunning Fourier infrared spectroscopic study of carcinogenesis in human endometrium, Biospectroscopy 2 (1996), 155-165.

[11] B.R. Wood, M.A. Quinn, F.R. Burden and D. McNaughton, An investigation into FTIR spectroscopy as a biodiagnostic tool for cervical cancer, Biospectroscopy 2 (1997), 253-256.

[12] M.A. Cohenford, T.A. Godwin, F. Cahn, P. Bhandare, T.A. Caputo and B. Rigas, Infrared spectroscopy of normal and abnormal cervical smears: evaluation by principal component analysis, Gynecol. Oncol. 66 (1997), 59-65.

[13] H.M. Yadzi, M.A. Bertrand and P.T.T. Wong, Detecting structural changes at the molecular level with Fourier infrared spectroscopy - a potential tool for prescreening preinvasive lesions of the cervix, Acta Cytologia 40 (1996), 664-668.

[14] B. Ragas and P.T.T. Wong, Human colon adenocarcinoma cell lines display infrared spectroscopic features of malignant colon tissues, Cancer Res. 52 (1992), 84-88.

[15] P.T.T. Wong, S. Lacelle and H.M. Yazdi, Normal and malignant human colonic tissues investigated by pressure-tuning FT-IR spectroscopy, Appl. Spectrosc. 47 (1993), 1830-1837.

[16] E. Benedetti, L. Teodori, M.L. Trinca, P. Vergamini, F. Salvati, F. Mauro and G. Spremolla, A new approach to the study of human solid tumor cells by means of FT-IR microspectroscopy, Appl. Spectrosc. 44 (1990), 1276-1280.

[17] H.P. Wang, H.C. Wang and Y.J. Huang, Microscopic FTIR studies of lung cells in pleural fluid, Sci. Total Environ. 204 (1997), 283-287.

[18] P.T.T. Wong, S.M. Goldstein, R.C. Goldstein, T.A. Godwin, C. Pivik and B. Rigas, Distinct infrared spectroscopic patterns of human basal cell carcinoma of the skin, Cancer Res. 53 (1993), 762-765.

[19] H. Fabian, M. Jackson, L. Murphy, P.H. Watson, I. Fichtner and H.H. Mantsch, A comparative infrared spectroscopic study of human breast tumors and breast tumour cell xenografts, Biospectroscopy 1 (1995), 37-45.

[20] M. Jackson, L.P. Choo, P.H. Watson, W.C. Halliday and H.H. Mantsch, Beware of connective tissue proteins: assignment and implications of collagen absorption in infrared spectra of human tissues, Biochem. Biophys. Acta 1270 (1995), $1-6$

[21] J.M. Sanchez-Ruiz and M. Martinez-Carrion, A Fouriertransform infrared spectroscopic study of the phosphoserine residues in hen egg phosvitin and ovalbumin, Biochemistry $\mathbf{2 7}$ (1988), 3338-3342. 
[22] S.E. Goelz, B. Vogelstein, S.R. Hamilton and A.P. Feinberg, Hypomethylation of DNA from benign and malignant human colon neoplasms, Science 228 (1985), 187-190.
[23] B.F. Trump and R.T. Jones, Diagnostic Electron Microscopy, Vol. 4, John Wiley Son, New York, 1983, pp. 248-258. 


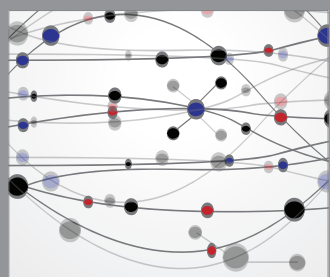

The Scientific World Journal
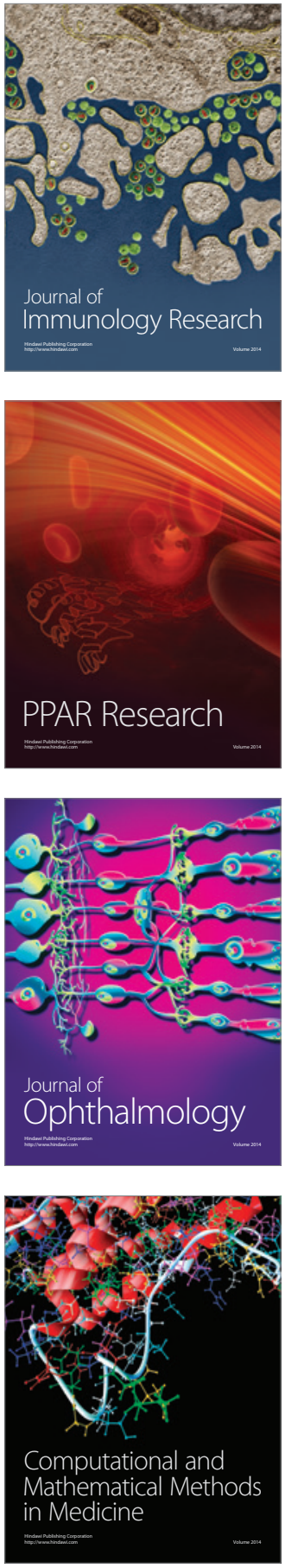

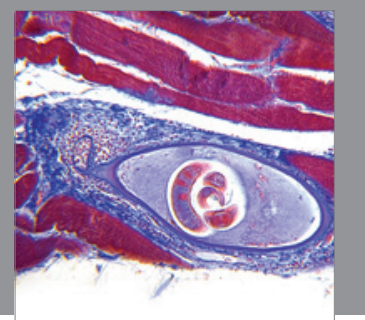

Gastroenterology

Research and Practice
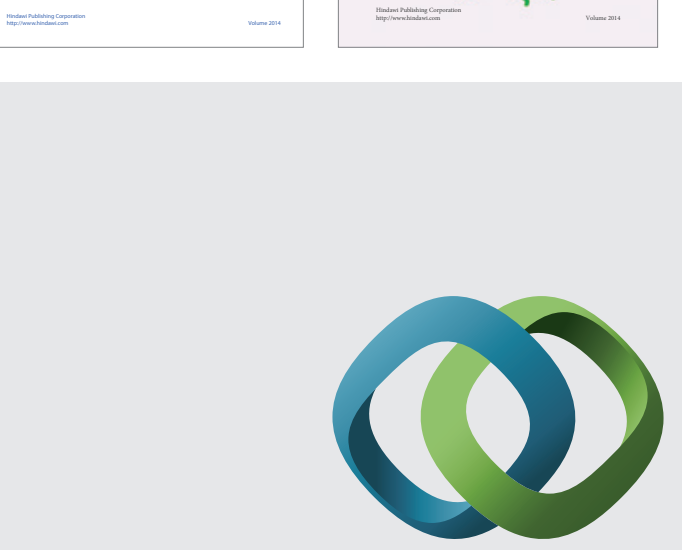

\section{Hindawi}

Submit your manuscripts at

http://www.hindawi.com
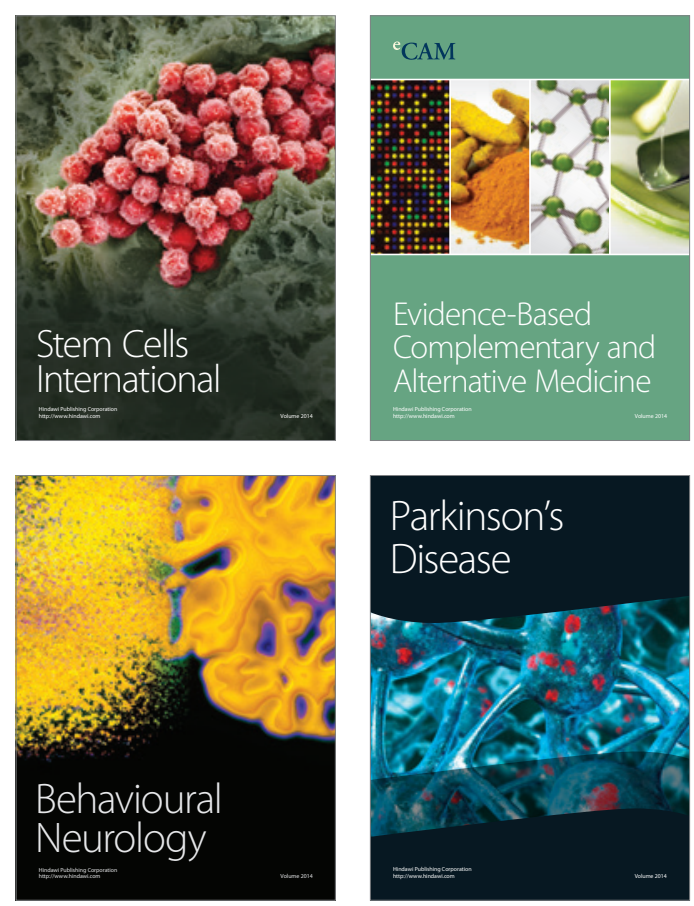

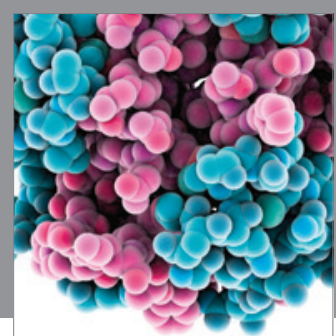

Journal of
Diabetes Research

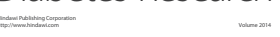

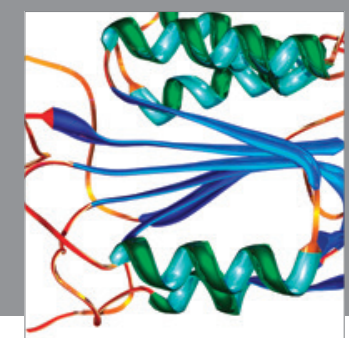

Disease Markers
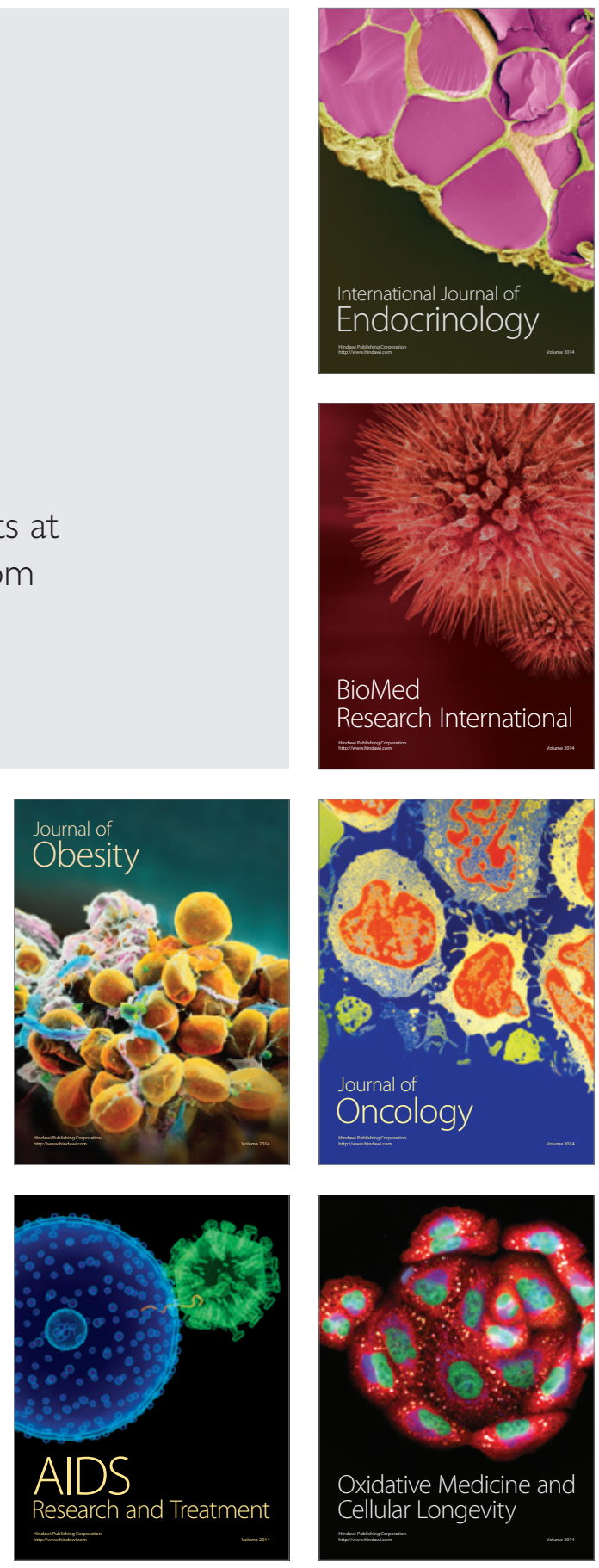